\title{
TRANSITION OF PRIMARY AND SECONDARY EDUCATION IN CROATIA TO ONLINE SCHOOLING: CHALLENGES AND NEW INSIGHTS
}

\author{
Klara Bilic Mestric, Jasna Tingle, Martina Hribar, Jasminka Maravic, \\ Croatian Academic and Research Network-CARNET, Croatia
}

\begin{abstract}
In the school year 2019/2020 during online schooling, 11 educators - teachers, head teachers and pedagogues kept reflective journals about their practice for three months, during which time they also participated in focus groups and individual sessions. Valuable data obtained through systematically conducted qualitative research led to the formulation of questionnaires for teachers, head teachers and parents, which were delivered at the end of the school year in July 2020. More than 26000 responses were collected. Taking a phenomenological perspective, this paper provides snippets into challenges faced by educators during online schooling and highlights their need for ICT-related education in Croatia.
\end{abstract}

Keywords: online schooling, COVID-19 and education, content-driven learning, Croatia

\section{Introduction}

Online education has been the subject of research for a number of decades, including the issues of openness, access, organisation, motivation, delivery methods, etc. However, the outburst of the COVID-19 virus in spring 2020 led to the transfer of complete national educational programmes to virtual environments, which gave distance learning a whole new dimension. By April 2020, 107 countries worldwide had closed their schools to prevent the spread of the COVID-19 virus pandemic and over a billion pupils were unable to attend classes at their schools (Viner et al., 2020; Azevedo et al., 2020). Croatia was no exception. On 11 March 2020, the Ministry of Science and Education issued a set of guidelines instructing the schools on preparatory activities concerning access to online platforms and the creation of online classrooms, thus ensuring that all teachers and head teachers received some instructions on online learning prior to its commencement. As of $16 \mathrm{March}$ 2020 , Croatian primary and secondary education was conducted in an online environment, 
and for the majority of pupils, it remained carried out in such manner until the end of the school year. For pupils in lower primary grades (aged 7 -11) educational programmes were broadcast through national television and individual communication channels between teachers and parents were established. Upper primary grade pupils (aged 11 - 14) and secondary school pupils (aged 14 - 18) were enrolled in virtual classrooms on various digital platforms, namely MS Yammer, MS Teams, Loomen and Google Classroom.

During the period of online schooling (16 March - 26 June), especially in its early stages, Croatia experienced an extreme form of social distancing. All events were banned and people took recommendations seriously by staying at home and avoiding social gatherings. Furthermore, most of the companies, which had the necessary resources, encouraged their employees to work from home. As a result, many parents had to balance their working from home with their children's online schooling. It is noteworthy that the massive fear produced by the pandemic (Strong, 1990) was enhanced by an earthquake of magnitude $5.3 \mathrm{Mw}$, which hit Zagreb and the surrounding region on $22 \mathrm{March}$.

In addition to the support provided by the Ministry of Science and Education, the Croatian Academic and Research Network - CARNET played an important role during the online schooling. CARNET has been enhancing the digital transformation of education in Croatia over the last two decades through various projects, such as e-Islands, Schools 2.0, e-Schools pilot project and an ongoing e-Schools programme. Due to a historically unprecedented situation concerning online primary and secondary education, by the end of March, CARNET had initiated research with practitioners in order to monitor and evaluate the online schooling that was taking place.

\section{Two lines of research}

Due to the novelty of the situation, a grass-roots approach was taken from the very beginning of the online schooling. CARNET contacted teachers, pedagogues and head teachers, invited them to keep reflective journals and participate in action research, which was aimed at developing reflective practice about the unprecedented teaching that took place. At the end of the qualitative research (also the end of the school year), a quantitative research was conducted, through which 26871 responses were obtained from teachers, head teachers and parents. The mixed methods research design was based on the exploratory sequential approach, in which conclusions of qualitative research are generalized with the help of quantitative research (Sekol \& Maurović, 2017).

In the qualitative research strand, conducted from March to June 2020, eleven educators regularly kept reflective journals and participated in focus groups and individual interviews. Participants, practitioners who were at the same time reflective researchers of 
their own educational practice, had been collaborating with CARNET on earlier projects. Over 220 pages of journal entries were collected and 13 focus groups and dozens of hours of individual interviews were held. This type of qualitative research provides insight into the actual practices of educators without the mediating lenses of external researchers, allowing practitioners to talk about topics they consider important at a pace that suits them (Meth, 2003). Reflective journals or research journals are a written trace left by practitioners during the research process, detailing what they do and why. During the implementation of the qualitative research, CARNET systematically monitored the journal entries and coded them using a phenomenological approach - identifying topics that proved important to the practitioners themselves, of which the most important are discussed below. A total of twenty topics were recorded and 564 citations were coded.

Quantitative research was carried out in July 2020. This research line aimed to verify the conclusions of qualitative research with a specific goal of gaining better insight into the infrastructural and educational needs of CARNET users related to digital technologies. The questionnaires were based on topics that proved to be most relevant during the qualitative research. In the questionnaire for head teachers, the topics were related to the organization of online schooling, communication and cooperation, and support. The questionnaire for teachers dealt with the topics of virtual classrooms, communication and cooperation, and conducting online teaching. Finally, the questionnaire for parents was divided into topics of online schooling, communication and collaboration, and support. The online questionnaires were sent to all primary and secondary schools in Croatia through CARNET's regular channels. In total, 26871 responses were collected, out of which 20717 were collected from parents, 535 from principals and 5619 from teachers.

This paper will address issues of transition of primary and secondary education in Croatia to online schooling and provide general implications for non-adult distance learning following phenomenological approach (Merleau-Ponty, 2004), namely - covering those topics that emerged as the most challenging to practitioners. In this respect, the paper is grounded in the corporeality, temporality, relationality and spatiality of human practise (Merleau-Ponty, 2004; van Manen, 2016), or in simpler terms - it will highlight the importance of body, time, others and the world as presented by practitioners themselves (Sohn et al., 2017). These existential givens were in the focus of reflective journals as the fear of the virus and the sense of an isolated body, detached from its usual social environment, prevailed. Moreover, the problem of time management in an online environment, with all its pedagogical implications, led the participants to write and talk about the physical, emotional and psychological pain they endured, especially in relation to the workload with pupils that was inadequately managed, which, in some cases, led to 
great fatigue, demotivation, isolation, loneliness, and, more extremely, burnouts in the case of teachers or depression in the case of pupils.

The paper argues that, with minor advances in ICT programmes offered at teacher training courses, the abovementioned challenges could be overcome or mitigated, not only in extreme, but also in normal circumstances. On the basis of the lived experience of the research participants, we will highlight their need for stronger implementation of ICT modules in teacher training programmes. However, we will not go into a detailed analysis of these programmes due to the focus of this paper on challenges of online schooling during the pandemic.

\section{Virtual schooling - real time and space problems}

The Guidelines issued by the Ministry of Science and Education included many instructions for head teachers, such as selection of one virtual platform for the whole school, organisation of the virtual staff room and virtual classrooms, but there were school procedures that were not covered by the Guidelines. Many head teachers expressed their puzzlement on how to organise classes for the lower primary grade pupils, pupils with special needs, pupils in branch schools and those with inadequate infrastructure. In some areas of Croatia are still not covered by the internet connection and in some cases pupils' families did not own necessary computer equipment. Quantitative data showed that $4 \%$ of the parents stated that their child did not have necessary equipment at home, while further $26 \%$ parents reported that equipment had to be shared among family members. All this led to some schools organising schooling in school premises. There was also a question of nonteaching school employees and their duties during online schooling - whether janitors, cleaners, accountants, secretaries should come to school, what can they do from home, etc.

Teachers' journals often speak about problems with time management. Though all Croatian teachers attended some online courses during curricular reform, a significant majority did not have any experience in creating or managing online courses. As a consequence, most teachers were not aware of the importance of structure in their online classes which can be achieved through activity plans, schedules, assignment deadlines or communication plans. Journals show constant boundaries and accessibility issues.

"Assignments are constantly arriving, 7 new groups on Viber and WhatsApp, and their motivation is falling day by day. I'm getting desperate. I spend all day reading and sending, explaining and replying to messages. I think this is solely because pupils don't have an authority figure in front of their eyes, do not see the teacher physically, so they don't have the impression 
Bilic Mestric, K., Tingle, J., Hribar, M., \& Maravic, J.

Transition of Primary and Secondary Education in Croatia to Online Schooling: Challenges and New Insights

that the teacher is reading and reviewing the assignment." (Teacher 3, a reflective journal entry, 24 March 2020)

During focus groups, teachers complained of never-ending homework corrections, and their writings showed that they stayed up late every night to finish corrections and prepare materials for the following day, which they sometimes failed to do. Some of them complained about physical pain due to constant sitting and time spent in front of a screen. Sometimes they also got angry about receiving pupils' emails late in the evening or during the night and they felt obliged to answer them immediately. In all journals, teachers expressed their dissatisfaction with the amount of work and time needed for online schooling and often found pupils accountable for this workload:

"Endless browsing of virtual classrooms, replying to emails, messages, updating data, helping my biological children with their tasks, searching for an adequate story for an extracurricular activity and, in the end, I forgot about the Zoom session." (Teacher 2, a reflective journal entry, 19 May 2020)

In this and other entries, the problem, from the teachers' perspective, seemed to lie in the pupils' perception of the nature of online classes - that they could pose questions any time, send their work late and expected immediate detailed feedback on the assignments they handed in. Also, the boundaries between private and professional were often blurred in their journal entries.

\section{Letting go of control - problems with (online) teaching methods}

Questionnaires showed that the majority of teaching was based either on sending basic presentations to pupils or asking pupils to complete the assignments found in their textbooks. Less frequently teachers used other methods of delivery, such as presentations enhanced with audio or video as well as occasionally using interactive materials in homeworks. Most commonly, the teaching was asynchronous. The result could be described as a content-driven self-study approach (Teräs et al., 2020) that seemed to be a dominant teaching method. Of 5619 teachers who responded, $30 \%$ stated that they sent presentations to their pupils once a week and further $27 \%$ did the same several times a week. At the same time, $27 \%$ of the teachers instructed their pupils to read parts of textbooks and answer several text related questions once a week, while around $20 \%$ did the same several times a week. The following quote from the qualitative study illustrates this approach:

\footnotetext{
"Browsing the content on Teams, I get the feeling that everyone's tired, the tasks are no longer as creative as in the beginning, teachers use what we said we would avoid - assign the task, pupils should read something, answer the
} 
Bilic Mestric, K., Tingle, J., Hribar, M., \& Maravic, J.

Transition of Primary and Secondary Education in Croatia to Online Schooling: Challenges and New Insights

questions, write the answer down in a notebook, take a picture and send it back." (Head teacher 1, a reflective journal entry, 7 May 2020)

Some teachers did explore creative ways in order to enhance their teaching. Teachers' journal entries revealed that, as time passed, some of them grew more confident and started using more varied tools and techniques.

"I made a PowerPoint presentation and added sound to it, that is, my voice. (...) but the challenge was recording the voice. I recorded the first sentence at least 7 times, :). I was surprised at how complex it actually was. One should think very carefully about what and how to say something, how to be clear, accurate, moderate, but not boring. (...), but I decided that I would not go on indefinitely because, at some point, I need to stop and send the children learning material." (Teacher 4, a reflective journal entry, 18 May 2020)

However, the earlier mentioned workload was a constant issue. Responses from parents' questionnaire revealed that more than $30 \%$ of parents spent a couple of hours daily helping their child with school assignments, while more than $70 \%$ reported helping their child in general. The workload, the amount of time teachers spent preparing classes and marking assignments, and the time parents spent helping with online schooling all testify to an enormous amount of content that teachers attempted to transmit. Furthermore, it testifies to the control teachers were used to having in the real classroom and to their attempt to retain it in an online environment.

The question of control became particularly evident in evaluation and assessment. In normal circumstances, summative assessment through written and oral exams based on the testing of factual knowledge prevails in Croatia. Curricular reform included training programmes for teachers with the goal of raising awareness of and promoting the importance of formative or assessment for learning (AFL). Unfortunately the programme was obstructed by the massive teacher strike in autumn 2019 and then the pandemic. A physical distance caused the participants to question the objectivity of the assessment process and results:

"I wonder to what extent the final grade (...) will actually be an objective presentation of the knowledge and abilities of each pupil?" (Head teacher 2, a reflective journal entry, 21 April 2020). 
Bilic Mestric, K., Tingle, J., Hribar, M., \& Maravic, J.

Transition of Primary and Secondary Education in Croatia to Online Schooling: Challenges and New Insights

\section{New communities of practice}

The challenges of online assessment also led teachers to rethink their assessment styles and to introduce new concepts and techniques. Many of them learned how to use online assessment tools such as Google Forms, but they also learned how to collaborate and develop rubrics together. One of the teachers who participated in qualitative research described the process of borrowing rubrics from a colleague and adjusting it to her classes:

"The last two days I have corrected some of the essays, but I have been mostly concerned with adapting the evaluation rubrics forwarded to me by a colleague. So far, I have modified it twice because I needed slightly different elements and definitely different instructions for each class, and I remembered to forward the first modified version to my other colleagues so that they would not have to do all the work." (Teacher 2, a reflective journal entry, 6 May 2020)

This was one of many forms where teachers, head teachers and pedagogues were learning together. Questionnaires showed that around 70\% percent of teachers and more than half of the head teachers accessed information on online schooling through collaboration with their colleagues, and journal entries are abundant with evidence of such practices:

"This is where my colleague's willingness to accept my idea came to the fore, and she used my work for her teaching (...). I must add that, in 'normal' circumstances, my colleagues and I did not have such forms of cooperation, but rather each of us did her own thing. Our previously mentioned good communication refers mainly to the transmission of information about pupils' behaviour (...). Joint planning of teaching content rarely happened, something we are both responsible for. It is for this reason that I was extremely pleased with her accepting my idea of using joint material in working with pupils." (Teacher 4, a reflective journal entry, March 2020)

Parents' answers also revealed that they mostly gained information about online schooling from homeroom teachers. Journal entries showed that collaboration with parents was especially important in lower primary grades where a parent was a channel between the teacher and the child. Parents were also a frequent theme of head teachers and pedagogue's journal entries and a topic of focus groups. In one of the entries, a pedagogue writes:

"My goal was to connect better with parents, invite them to cooperate, understand and support us in the new situation. According to the feedback from class teachers, parents accepted my request well and were encouraged 
Bilic Mestric, K., Tingle, J., Hribar, M., \& Maravic, J.

Transition of Primary and Secondary Education in Croatia to Online Schooling: Challenges and New Insights

to come in person if they wanted." (Pedagogue 3, a reflective journal entry, 3 March 2020).

\section{Project-based competence development}

Most of the participants of the qualitative research strand were from the schools that were involved in previous CARNET's projects: some of them worked in digitally mature schools (Balaban et al., 2018), and some were ICT enthusiasts and pioneers of ICT implementation in their schools. Therefore, it came as no surprise that reflective journals and focus groups revealed that participants who had extensive experience with digital technologies felt they had been prepared for a situation where all classes were conducted in a virtual setting:

"Digital competencies that we developed in the training through the eSchools pilot project significantly helped us, so we relatively quickly prepared for (...) communication with pupils and parents, and with each other." (Pedagogue 1, a reflective journal entry, introductory part).

"Online classes did not surprise me, I felt completely prepared to accept all the challenges. Digital technologies have been something I have been living with every day for the last seven years, ever since CARNET'S E-learning Academy. I develop my competencies every day out of personal curiosity, and inner motivation is something that always drives me. In online teaching, I didn't expect problems working with technology. The human factor turned out to be a challenge at every step of the way." (Teacher 1, a reflective journal entry, introductory part).

However, journals from participants who had no previous project experience revealed no such confidence. Moreover, it was confusion and insecurity that were recorded in the first weeks of online schooling.

"Online schooling found us all relatively unprepared. Unprepared in terms of teaching methods for distance learning, less in terms of digital technologies. (...) we quickly learned how to work in Teams. First, we educated teachers from lower primary grades, and they helped subject teachers. (...). The first week of classes was chaotic. We didn't know what to do, but as time went on, the teachers, the school improvement service and the principal coordinated and arranged the educational work. Students and parents needed to adjust a little more." (Pedagogue 2, a reflective journal entry, 30 March 2020) 
"Fear and insecurity are felt in the teachers. A few teachers who felt that they would not need digital skills are learning from more experienced colleagues." (Head teacher 1, a reflective journal entry, 17 March 2020)

Quantitative data show that these testimonies were by no means isolated examples of such insecurity. Though a significant number of teachers expressed they had no need for extra education ( $42 \%$ out of 5619 responses), in responses to an open question regarding specific support they needed, a recurring answer was that they would benefit from extra education on teaching methods in an online environment. What was highlighted in both journals and in questionnaire responses was a need to develop skills required for teaching in an online environment.

\section{Conclusion}

In this paper, we presented issues regarding online schooling that turned out to be the most relevant from the perspective of teachers, pedagogues and head teachers. The findings show that ICT-related confidence levels of all these groups of educators depended on their previous personal or school experience. However, the data also showed that, experience notwithstanding, the workload led to feelings of isolation, anger, burnout and sometimes even physical pain. The workload was largely related to the content-driven self-study method the online schooling was based on, and the control-centred educational system. Research findings did not only provide valuable insights into the weaknesses of online schooling, but of the Croatian educational system in general. Project-based professional development is of particular benefit for participating schools, but it is also discriminatory as not all schools have equal access to resources and the ability to apply for or participate in such projects. Furthermore, the fact that teachers shared similar workload problems leads to the conclusion that future and in-service teachers in Croatia need further training that will endorse innovative teaching and assessment methods in the virtual, but also the real environment. Finally, sharing and collaboration models developed during online schooling indicate the importance of informal learning and the often underestimated role parents have in the Croatian educational system.

\section{References}

Azevedo, J. P., Hasan, A., Goldemberg, D., Iqbal, S. A., \& Geven, K. (2020). Simulating the potential impacts of covid-19 school closures on schooling and learning outcomes: A set of global estimates. World Bank Group, June 2020.

Balaban, I., Redjep, N. B., \& Calopa, M. K. (2018). The analysis of digital maturity of schools in Croatia. International Journal of Emerging Technologies in Learning (iJET), 13(06), 4-15. 
Bilic Mestric, K., Tingle, J., Hribar, M., \& Maravic, J.

Transition of Primary and Secondary Education in Croatia to Online Schooling: Challenges and New Insights

Croatian Academic and Research Network - CARNET (2020). Retrieved from https://www.carnet.hr/en/

van Manen, M. (2014). Phenomenology of practice: Meaning-giving methods in phenomenological research and writing. Walnut Creek, CA: Left Coast Press.

Merleau-Ponty, M. (2004). The world of perception. New York \& London: Routledge.

Meth, P. (2003). Entries and omissions: using solicited diaries in geographical research. Area, 35(2), 195-205. doi: 10.1111/1475-4762.00263

Sekol, I., \& Maurović, I. (2017). Miješanje kvantitativnog i kvalitativnog istraživačkog pristupa u društvenim znanostima-miješanje metoda ili metodologija? Ljetopis Socijalnog Rada/Annual of Social Work, 24(1), 7-32. https://doi.org/10.3935/ljsr.v24i1.147

Sohn, B. K., Thomas, S. P., Greenberg, K. H., \& Pollio, H. R. (2017). Hearing the voices of pupils and teachers: A phenomenological approach to educational research. Qualitative Research in Education, 6(2), 121-148. doi:10.17583/qre.2017.2374

Strong, P. (1990). Epidemic psychology: a model. Sociology of Health \& Illness, 12(3), 249259. https://doi.org/10.1111/1467-9566.ep11347150

Teräs, M., Suoranta, J., Teräs, H., \& Curcher, M. (2020). Post-Covid-19 Education and Education Technology ‘Solutionism': a Seller's Market. Postdigital Science and Education, 2, 863-878. https://doi.org/10.1007/s42438-020-00164-X

Viner, R. M., Russell, S. J., Croker, H., Packer, J., Ward, J., Stansfield, C., Mytton, M., Bonell, C., \& Booy, R. (2020). School closure and management practices during coronavirus outbreaks including COVID-19: a rapid systematic review. The Lancet Child \& Adolescent Health, 4, 397-404. https://doi.org/10.1016/S2352-4642(20)30095-X 